\title{
Subject Unique Identifier
}

National Cancer Institute

\section{Source}

National Cancer Institute. Subject Unique Identifier. NCI Thesaurus. Code C69256.

A unique identifier for a person who is the subject in a study. 